\title{
VIOLÊNCIAS E RESISTÊNCIAS NO ESPAÇO ESCOLAR: CONTRIBUIÇÕES PSICANALÍTICAS
}

\author{
VIOLENCE AND RESISTANCE IN SCHOOL: PSYCHANALYTIC \\ CONTRIBUTIONS
}

\author{
Mariana Rocha Bonin Ribeiro ${ }^{60}$ \\ Marília Etienne Arreguy ${ }^{61}$
}

\begin{abstract}
RESUMO
Este trabalho objetiva compreender de que forma o mal-estar se apresenta nos docentes e estudantes, considerando a resistência psíquica, do ponto de vista da obra freudiana, como uma resposta silenciosa às inúmeras violências vividas no cotidiano escolar. A pesquisa pautou-se numa abordagem qualitativa, elencando tipos de resistência intrapsíquica, e utilizou como método de sensibilização a entrevista semiestruturada em escolas de Niterói. Ao passo que os jovens falavam livremente para as pesquisadoras acerca da dificuldade de assumirem suas escolhas identitárias em relação ao discurso violento dos pais e das dificuldades que encontravam na escola, verificou-se que os professores apresentam mais resistências ao falar sobre a violência escolar. Suas resistências surgiam através da violência projetada nos estudantes e do silêncio como principal elemento capaz de os eximirem da questão. A resistência dos professores conotava certo temor ao suposto olhar investigativo da pesquisadora.
\end{abstract}

Palavras-chave: Resistência. Psicanálise. Professores. Violência. Mal-estar.

\section{ABSTRACT}

The violence in school is a major concern in modern society. For this reason, this study aims to analyze school violence in the discourse of teachers and students. The research was based on qualitative method supported by semistructured interviews with teachers and conversations with groups of students in a context of "occupation". The study was localized in three schools in the city of Niterói. The analysis was based on literature review in respect to concept of resistance on the work of Sigmund Freud. The students reported violent conflicts in revealing their sexuality choices to their parents and talked openly about several violent situations they have leaved. Their resistance was directed toward their family and they were looking for some help from the researchers. On the other hand, the resistance appears in the teachers discourse as a silence, when them are supposed to lost their capacity to access unconscious violence in themselves. Teacher's resistances seems to reveal a kind of fear of the researchers.

Keywords: Resistance. Psychoanalysis. Teachers. Violence. Discontents.

\footnotetext{
${ }^{60}$ Mariana Rocha é psicóloga pela FAMATH e estudante de Pedagogia pela UNIRIO. Atualmente trabalha em consultório particular sob o referencial psicanalítico e é professora de séries iniciais. Desenvolveu este Projeto de Iniciação Científica como aluna bolsista CAPES no ano 2015-2016. https://orcid.org/00000001-7329-0123

${ }^{61}$ Marília Etienne Arreguy é psicanalista, pesquisadora-convidada na École Doctorale de Recherches em Psychanalyse et Psychopathologie - Université Paris Diderot. Orientadora do projeto. https://orcid.org/0000-0002-4157-0128
} 


\section{RevistAleph}

\section{INTRODUÇÃO}

Esta pesquisa teve como tema central o estudo teórico do conceito freudiano de resistência ${ }^{62}$ tomado como mote para compreender a violência que perpassa as relações escolares e atravessa os processos psíquicos daqueles que se inserem nesse contexto. O trabalho pretendeu observar quais resistências estão presentes desde 0 primeiro contato das pesquisadoras-psicanalistas em campo, no encontro com os atores escolares. Por fim, observamos quais resistências se apresentaram nos discursos dos professores quando nos propusemos a escutar e intervir sobre o tema "violência escolar".

Neste estudo, atentamo-nos para algumas formas de tratar a violência, trazidas por Costa (2003). Este autor analisa criticamente as dificuldades que surgem ao falar deste tema, afirmando que a violência "sofre polarizações" - ora é tratada como um tabu (através da impossibilidade de falar sobre); - ora, é tratada de uma "aura romântica-pessimista" (que torna a violência uma categoria irredutível de análise e, portanto, de impossível solução). Nesses dois exemplos, é possível observar as dificuldades que emergem no discurso docente e discente, traçando um paralelo àquilo que Freud (1930) já mencionou sobre as impossibilidades de falar sobre o mal-estar ${ }^{63}$.

Costa (ibid) tece duas análises que chamaram a atenção, justamente por se tratar de um psicanalista que as faz. A primeira delas é a ideia de que a Psicanálise entra no "compasso das ideologias modernas" para tratar da violência, diluindo seu impacto e atenuando seus efeitos. Se, por um lado, consideramos isso um ponto positivo, pois desmistifica o conceito e permite aproximações e estudos, por outro, incorremos no erro de naturalizar as produções violentas e desconsiderar aspectos sociais ${ }^{64}$ que contribuem para tal fenômeno. Hoje, o tema da violência nas escolas é considerado

\footnotetext{
${ }^{62} \mathrm{~A}$ resistência é definida por Laplanche e Pontalis (1996) como "tudo o que nos atos e palavras do analisando, durante o tratamento psicanalítico, se opõe ao acesso deste ao seu inconsciente" (p. 458460). Numa síntese deste conceito, os autores destacam o caráter vexatório conferido ao retorno do conteúdo psíquico recalcado, que revela os desejos inconscientes e constitui-se como algo que sempre dificultou toda e qualquer conversação bem como toda análise.

${ }^{63}$ Este tema é abordado no texto de Freud: "Mal-estar na civilização" (1930).

${ }^{64}$ Neste rol podemos elencar alguns: miséria, desinvestimentos estatais, intolerâncias diversas (xenofobia, racismos, machismo) ...
} 


\section{RevistAleph}

como "amplamente discutido", como apontam Moura e Ferreira (2005). No entanto, o que se configura como relevante neste trabalho é a suposição de que, embora existam inúmeros estudos sobre o tema, tratar sobre este assunto ainda produz muitas resistências, principalmente nos professores.

A violência assume diferentes formas sociais, sejam estas diretas ou indiretas. Quando se trata de violência escolar, podemos dizer que as múltiplas ramificações não permitem uma conceptualização universal que abranja todas as experiências vividas neste contexto. Podemos, no entanto, considerar que a violência simbólica (BOURDIEU, 1990; ARREGUY, 2014; ARREGUY \& COUTINHO, 2015; NOGUEIRA \& NOGUEIRA, 2004) atravessa as relações construídas no espaço escolar porque, além das agressões verbais e físicas sofridas por alunos e professores, outros aspectos invisíveis da violência estão presentes e reverberam no psiquismo dos que estão envolvidos.

A ação pedagógica seria em si uma forma de violência simbólica, pois converteria um arbitrário cultural em cultura legitimada pelo saber escolar, sendo uma forma de imposição da diferença de classes. A respeito disso, Nogueira \& Nogueira (2002) dizem:

De acordo com essa concepção, nenhuma cultura pode ser objetivamente definida como superior a nenhuma outra. Os valores que orientariam cada grupo em suas atitudes e comportamentos seriam, por definição, arbitrários, não estariam fundamentados em nenhuma razão objetiva, universal. Apesar de arbitrários, esses valores - ou seja, a cultura de cada grupo - seriam vividos como os únicos possíveis ou, pelo menos, como os únicos legítimos. Para Bourdieu, o mesmo ocorreria no caso da escola. A cultura consagrada e transmitida pela escola não seria objetivamente superior a nenhuma outra. O valor que the é concedido seria arbitrário, não estaria fundamentado em nenhuma verdade objetiva, inquestionável. Apesar de arbitrária, a cultura escolar seria socialmente reconhecida como a cultura legítima, como a única universalmente válida (p. 28).

Pensando nos substratos invisíveis da violência, utilizamos então a teoria psicanalítica, para o entendimento deste trabalho. Por não ser possível delimitar as inúmeras violências sofridas pelos professores, a pesquisa situou algumas situações como ponto de partida para a escuta de campo: - as exigências que sofrem os docentes no que diz respeito à produtividade, - as relações hierárquicas/dominantes dentro da 


\section{RevistAleph}

escola; - as limitações do conteúdo a ser dado em sala por conta do currículo65; - a obrigatoriedade das avaliações dos alunos; - a escassez de materiais (sobretudo na rede pública) à disposição do professor para elaboração de provas e trabalhos; - a ausência de espaços e profissionais para tratar de questões relativas ao fazer docente (destacamos aqui o trabalho psicológico e a importância de sua escuta); - e, por fim, mas não menos importante, as dificuldades encontradas nas relações com alunos e pais.

A violência entre alunos e professores é abordada em discursos que ora responsabilizam os jovens, ora os professores. Ousamos, com inspiração no sonho democrático de Paulo Freire, praticar a escuta dos professores nas instituições. Como afirma Freire (1996): "somente quem escuta paciente e criticamente o outro, fala com ele" (p.113). Ainda sobre o ato de escutar, ele o define como "a disponibilidade permanente por parte do sujeito que escuta para a abertura à fala do outro" (p.119). Desta forma, ao mesmo tempo em que colhíamos material de pesquisa, falávamos aos professores através de nossa escuta. Embora Paulo Freire jamais tenha sido psicanalista, certamente, dominava a arte de uma escuta sensível.

Buscamos, através da técnica da escuta psicanaliticamente orientada, ir mais além do que as pesquisas quantitativas pretendiam ao enumerar a quantidade de atos violentos nas escolas e mapear escolas mais e menos violentas. Coube-nos, como definiu Charlot (2005), após esse comentário inicial sobre o tema violência e sobre as impossibilidades de definição deste conceito, fazer advir o ser humano, buscando relativizar discursos que colocam o professor na posição de objeto destinado a percorrer os caminhos do magistério devocional. Como Charlot (2005) afirma:

\footnotetext{
"Violência" é o nome que se dá a um ato, uma palavra, uma situação, etc., em que um ser humano é tratado como um objeto, sendo negados seus direitos e sua dignidade de ser humano, de membro de uma sociedade, de sujeito insubstituível. Assim definida, a violência é o exato contrário da educação, que ajuda a advir o ser humano, o membro da sociedade, o sujeito singular (p. 24-25).
}

\footnotetext{
${ }^{65}$ Embora compreendamos que currículo mínimo não é máximo, o estabelecimento de conteúdos obrigatórios $\mathrm{x}$ tempo a ser ministrado encarceram o professor num modelo positivista em relação ao saber/conhecimento.
} 


\section{RevistAleph}

Bernard Charlot (ABRAMOVAY, 2005) apresenta uma discussão sintética e potente sobre o papel da violência como categoria de análise, no prefácio de uma pesquisa extensa da UNESCO ${ }^{66}$ sobre violência nas escolas. Ele diz considerar "elegante" o uso do vocábulo violência para dar margens às queixas subjetivas, mas aponta para o risco da vitimização e da relativização do termo. No capítulo 2, intitulado "Relações sociais na escola: encontros e desencontros", cujo foco são as relações entre os alunos, a pesquisa, em boa parte, apresenta dados quantitativos de agressões, ameaças, discriminações, presença de armas, furtos e medidas punitivas realizadas pela escola. Como forma de equacionar esse problema de modo disciplinar, os pesquisadores recomendam (UNESCO, 2005):

Uma forma de se antecipar aos conflitos é recorrer a sistemas de proteção, tais como o controle nos momentos de entrada e saída, seja de membros da comunidade escolar, seja de familiares dos alunos ou de indivíduos que habitam nas imediações da escola. Também se recorre ao uso de crachá e ao uniforme (p.361).

Salientam-se, portanto, práticas modernas - já bem delineadas pela análise foucaultiana dos micropoderes e do esquadrinhamento do espaço e do tempo nas relações institucionais, baseadas no controle e na punição (FOUCAULT, 1975/2019) como alternativa para manter a disciplina e, supostamente, evitar os conflitos violentos. Mais a frente, o trabalho da UNESCO também considera a importância do diálogo entre os pares da escola, embora nomeie de "ambíguo" o sentido do diálogo para alunos, uma vez que o diálogo com os pais pode ser considerado um castigo.

Embora a pesquisa da UNESCO pressuponha a análise dos professores sobre o fenômeno violência, isso não é enfatizado. Isso pode se relacionar à concepção que o Banco Mundial (BM) faz sobre os professores, pensando-os como "becos sem saída", ou, por assim dizer, como um tipo de investimento que 'não traz retorno'. A respeito disso, Torres (1996), salienta:

O tema docente, em geral, é um tema que incomoda atualmente o BM - e a sociedade em geral - e sobre o qual o Banco mantém posições ambíguas, inconsistentes e inclusive contraditórias. Os professores

66 Organização das Nações Unidas para a Educação, a Ciência e a Cultura. 


\section{RevistAleph}

costumam ser vistos principalmente como um sindicato, e sindicato magisterial lembra automaticamente reivindicação salarial, corporavistimo, intransigência, greve, quando não simples corrupção e manobra política. Os professores (e seus sindicatos) são vistos como problemas antes que recurso, "insumo" educativo necessário porém caro, complexo e difícil de lidar. Os mesmos professores, e não somente a sua formação, costumam de fato ser vistos como um "beco sem saída" (p. 160-161).

Embora o objetivo da pesquisa não seja avaliar o papel das empresas supranacionais na política educacional contemporânea, consideramos que ela é parte do mal-estar docente e da violência sofrida por essa categoria, pois trata-se de algo que atravessa as produções subjetivas, o fazer pedagógico e as relações cotidianas. Analisar os fenômenos psíquicos dos professores sem compreender a magnitude das suas dificuldades é limitar a discussão a um modelo puramente clínico e acrítico. Não pretendemos também lançar um conceito apriorístico de violência, mas nos aproximarmos dos professores com objetivo de escutá-los, já que nossa hipótese é de que, para nossos entrevistados (e, certamente, para a grande maioria dos professores), ainda é difícil tratar deste tema. Consideramos, pois, as resistências tanto da pesquisadora, quanto dos agentes da Instituição, prioritariamente os professores, com objetivo de entender quais são as dificuldades que atravessam o fazer-pesquisa em educação, sobretudo no que concerne ao tema da violência e as resistências em falar disso.

\section{O conceito de resistência na obra freudiana}

Ao longo de 40 anos da clínica freudiana, a preocupação em entender os mecanismos psíquicos inconscientes se fez presente. O desejo de compreender o que estava por trás de atos e sintomas conduziu todo o percurso clínico do médico e o fez repensar a sua posição e a sua própria técnica, inúmeras vezes, com destaque para o importante ponto de virada com o abandono do método hipnótico-sugestivo. Deixar falar livremente era algo subversivo na época.

Na obra canônica Estudos sobre a Histeria, especificamente no texto de 1893, intitulado "A psicoterapia da histeria", Freud relata as dificuldades sobre o tratamento 


\section{RevistAleph}

com a hipnose ao afirmar: “(...) deparei com a dificuldade de que muitos pacientes não eram hipnotizáveis, embora seu diagnóstico fosse de histeria e parecesse provável que o mecanismo psíquico por nós descrito atuasse neles." (p.292) Mais à frente, ele completa: "Notei, contudo, que em alguns pacientes o obstáculo era ainda mais arraigado: eles recusavam até mesmo qualquer tentativa de hipnose" (p.293).

O momento de grande significância que marca a mudança de concepção sobre o método hipnótico e aponta para o início do estudo sobre as resistências está presente no caso de Frau Emmy von N. (ibid.). Ao falar durante a análise: "Fique quieto! Não diga nada! Não me toque!" (FREUD, 1889, p. 86), Emmy coloca em questão a vulnerabilidade da técnica sugestiva e o papel da resistência do paciente no processo analítico. Nesse contexto, Freud percebe que o estado psíquico provocado pela hipnose não permitia compreender as resistências das pacientes e fundamenta sua técnica de associação livre passando a utilizá-la na escuta do sofrimento da histeria.

A escuta a partir das associações livres de suas pacientes fez com que Freud percebesse que muitas lembranças eram relatadas mesmo sem a aplicação do método hipnótico, aliás, a narrativa muitas vezes recuava ainda mais no passado quando não era aplicada a técnica. Outro fator importante estava no fato de que muitas pacientes continuavam a lembrar do que haviam falado durante a hipnose quando já estavam em vigília. Contudo, quando davam prosseguimento a essas memórias em análise, costumavam dizer que não sabiam nada a respeito ou descreviam-nas como obscuras e apresentavam dificuldades em seguir com o relato. Freud passou então a considerar que existem forças que impediriam o trabalho com o conteúdo recalcado, mesmo utilizando a técnica da associação livre. Essas forças estariam presentes de diferentes formas no transcorrer de uma análise.

Na série de casos clínicos que Freud relata ainda nos Estudos sobre a Histeria, as histórias da Srta. Anna O. e da Sra. Elisabeth Von R. ilustram as resistências que irrompem ao longo do tratamento. Enquanto a primeira se negava a realizar o exame de sensibilidade cutânea por lhe gerar sentimentos de angústia, a segunda encontrava 


\section{RevistAleph}

dificuldades em rememorar os acessos de dor ${ }^{67}$. Ambas as situações tinham relação com suas resistências psíquicas e representavam um modo de impedir o acesso do médico ao conteúdo recalcado. Nesses dois casos, o que estava em questão, isto é, interditado e lançado para fora da consciência, era a paixão pelo pai e pelo cunhado, respectivamente. Portanto, tratava-se de algo indizível, posto que gravemente proibido.

Nesse momento Freud ainda era adepto à técnica de pressão das mãos ${ }^{68}$, a qual ele não abandonou prontamente ao romper com o método hipnótico. Acreditava que essa técnica sugestiva auxiliava no manejo com as resistências, uma vez que desviava a atenção da paciente de tudo o que Ihe prendia a atenção voluntariamente, e que a insistência do analista era capaz de trazer à luz os grupos de representações psíquicas patogênicas. No entanto, ele colocava limites a esse tipo de trabalho, ao afirmar que a insistência em pressionar a mão sobre a cabeça da paciente por parte de um médico não familiarizado com a sugestão, quer dizer que ele não era capaz de lidar com a resistência presente nos casos mais graves de histeria.

Assim, mesmo a técnica de pressão na cabeça oferecia resistências ao paciente. As fragilidades de sua aplicação são observadas por Freud (Op. cit.) ainda em " $A$ psicoterapia da histeria":

A técnica da pressão nada mais é do que um truque para apanhar temporariamente desprevenido um ego ansioso por defender-se. Em todos os casos mais ou menos graves o ego torna a relembrar seus objetivos e oferece resistência (p. 302-303).

Esse texto ainda apresenta sua importância, pois nele Freud aponta para as outras formas de resistência que encontrou sob análise: 1) No esquecimento do compromisso da análise, mesmo tendo concordado de antemão; 2) Dizendo que nada Ihe ocorre a cabeça; 3) Retendo informações por julgá-las sem importância ou aflitivas;

\footnotetext{
${ }^{67}$ Elisabeth também dizia a Freud (1893) sobre suas tentativas de hipnotizá-la: "Não estou dormindo, sabe; não posso ser hipnotizada" (p.175).

${ }^{68}$ Com auxílio do toque sobre a testa a fim de fazê-lo lembrar sobre algum evento esquecido pelo estado "limitado" de consciência, o paciente deveria dizer sobre o que lhe viesse à mente, não importando qual fosse o conteúdo.
} 


\section{RevistAleph}

4) Através de desculpas ${ }^{69}$; 5) Trazendo informações importantes como se não tivessem significância ${ }^{70}$; 6) Pela interrupção entre as ideias; 7) Pela impossibilidade de solução do conteúdo recalcado para o paciente; 8) e pela aparição de imagens mnêmicas incompletas.

De acordo com o médico, o psiquismo é formado por camadas. O conteúdo de cada camada se relaciona a um grau de resistência e esse grau aumenta na medida em que se aproxima o núcleo patogênico. O tratamento analítico consistiria em remover as resistências, uma a uma, no tempo do paciente, uma vez que as ideias estariam perto do núcleo patogênico que o paciente renega em reproduzir. Era preciso ir pela periferia da estrutura psíquica, fazendo-o lembrar de apenas o que fosse capaz de suportar, a fim de superar suas resistências pouco a pouco.

Não havia, entretanto, garantias de que o paciente apresentasse o caminho para o conteúdo recalcado, pois, na maioria das vezes, seu discurso revelava uma completude e autossuficiência capaz de enganar uma escuta desatenta. Freud apontou que era através das lacunas e imperfeições do relato que o analista seria capaz de perceber o fio condutor que levaria às ideias patogênicas.

No decorrer de sua obra, outras estruturas psíquicas são alvo de estudo sobre suas relações com as resistências. No texto Observações adicionais sobre as neuropsicoses de defesa (1896), ele discorre sobre a histeria, a neurose obsessiva e a paranoia. Na histeria, a resistência estaria na impossibilidade de lembrar-se do fato traumático; na neurose obsessiva, a representação da ideia (distorcida) é um compromisso da resistência com o produto intelectual patológico surgido em rituais e comportamentos sintomáticos e, na paranoia ${ }^{71}$, haveria um comprometimento das resistências que enfraqueceriam as autoacusações - o sujeito não as reconheceria mais

\footnotetext{
${ }^{69}$ Dá como exemplo a fala de uma paciente que diz "Minha cabeça hoje está distraída, o relógio (ou o piano da sala ao lado) está me perturbando" (FREUD, 1893, p. 303).

70 Freud nomeia de "Um príncipe de ópera disfarçado de mendigo" às ideias que emergem na análise, mas que são destituídas de valor pelo paciente. Nessas ideias aparentemente irrelevantes, o processo de defesa transformou uma representação forte em fraca, pois roubou o seu afeto. É preciso que o analista a considere.

${ }^{71} \mathrm{O}$ caso de $\mathrm{P}$. ilustra as tentativas de Freud em compreender a estrutura paranoide à luz dos seus estudos sobre as outras neuroses. Percebeu o médico nesse caso que existiam resistências nas pacientes, mas que estavam enfraquecidas.
} 


\section{RevistAleph}

e elas retornariam na forma de representações delirantes (como a acusação ao outro, típica dos fortes mecanismos de projeção).

Outra forma de resistência é pormenorizada no texto $O$ mecanismo psíquico do esquecimento (1898). Neste sucinto artigo, Freud relata uma experiência pessoal, na qual havia esquecido o nome de um artista (Signorelli). Ao analisar esse fato em cadeia associativa, compreende que a obra do pintor relacionava-se aos temas da morte e da sexualidade, e que, de algum modo, isso havia provocado resistência quanto à sua rememoração. Sobre isso ele diz: "Recordei-me então de que essas representações recalcadas nunca me haviam absorvido mais do que algumas semanas antes, depois de ter recebido uma certa notícia"72 (FREUD, 1898, p. 281).

Freud, ainda neste trabalho de 1898, fala que a memória possui “restrições por tendência da vontade" (p. 283). Dessa forma, o inconsciente é capaz de omitir informações por conta da resistência inconsciente. Quando uma paciente histérica lhe disse: “(...) eu de fato já sabia disso desde a primeira vez, mas era justamente o que eu não queria dizer"73 (FREUD, 1893, p. 139), acabou por demonstrar a seletividade do material produzido pela resistência no plano inconsciente, bem como a possibilidade de relembrar do conteúdo recalcado após a superação das resistências. A fala desta paciente revela justamente aquilo que inconscientemente escondia, movida por uma resistência seletiva.

O esquecimento é ainda alvo dos estudos de Freud (1900) no clássico: $A$ interpretação dos sonhos. Ele relata que o fato de esquecer o conteúdo do sonho é produto de uma resistência fortalecida no estado de vigília, porém arrefecida no momento da formação do material onírico. Quando um paciente relatava ter se esquecido do sonho, Freud aplicava-Ihe a técnica de pressão para tentar recobrar sua memória. Uma vez superada a resistência via sugestão, era possível lembrar-se não somente daquele, mas também de outros sonhos produzidos na mesma noite.

\footnotetext{
${ }^{72}$ A notícia era do suicídio de seu paciente, acometido por uma perturbação sexual incurável.

${ }^{73}$ A esse não querer saber, Freud atribui o discurso da histérica e ao seu desejo inconsciente de não querer saber sobre o mal que lhe acomete.
} 


\section{RevistAleph}

Os sonhos são parte do terreno em que Freud se apropria para pensar a produção do material inconsciente não apenas como algo patológico, mas como aquilo que move o psiquismo humano de um modo geral. Ele identifica que as resistências estão presentes tanto no processo de formação do sonho quanto na evocação deste em estado de vigília. Ocorre que, no estado do sono, há uma diminuição do poder das resistências, o que possibilita a realização de desejos proibidos e certa elaboração onírica desses conteúdos conflitivos, insuportáveis em estado consciente.

Os mecanismos de defesa que compõem o sonho são o deslocamento e a condensação (FREUD, 1900). Ambos surgem como forma de escapar da censura imposta pela resistência, ou seja, "disfarçam" o conteúdo interditado através de outras formas de representação, indiretas, dada a resistência face ao recalcado. Assim, chama a atenção a censura e a distorção presentes na formação dos sonhos. Na transferência clínica por parte do paciente, a omissão e/ou alteração do conteúdo original também podem manifestar-se na forma de dissimulação, como uma resistência à interpretação na análise (FREUD, 1900). Assim, as resistências psíquicas, embora possam ser atenuadas, estão sempre ativas, seja no sonho, seja no discurso.

No texto Cinco Lições de Psicanálise (1910 [1909]), Freud destaca as principais ações da resistência, como aquelas que "exprimem impulsos e intenções que devem ficar ocultos à própria consciência (...)" (p.50), a saber: fuga temporária de nomes próprios; lapsos de linguagem, atrapalhações na execução de atividades, perda ou quebra de objetos; algumas distrações e desatenções, trautear melodias, brincar com objetos, com partes da roupa ou do próprio corpo, etc. Essas causalidades se aproximam da definição de atos falhos nos quais "o homem trai, em regra, os mais íntimos segredos" (ibid., p. 50).

Freud ainda tratou de outra importante forma de produção da resistência: a repetição. Em seu texto Recordar, repetir e elaborar - Novas recomendações sobre a técnica da psicanálise, Freud (1914) percebe que as resistências que impediam o rememoramento apareciam na repetição das lembranças em forma de atuação. A respeito disso, ele diz que "(...) o paciente não recorda coisa alguma do que esqueceu e reprimiu, mas expressa-o pela atuação ou atua-o (acts it out). Ele o reproduz não como 


\section{RevistAleph}

lembrança, mas como ação; repete-o, sem, naturalmente, saber o que está repetindo" (ibid., p.165).

Ele comenta que essa repetição se relaciona com a transferência ${ }^{74}$, pois ela representa algo que está ligado a um passado esquecido. A própria transferência é em si um fragmento da repetição. Quanto maior for o esquecimento em decorrência da resistência, maior será a atuação (acting out) do paciente.

De acordo com Freud, a repetição estaria presente no processo inicial da análise. Essa repetição, ao passo que dificulta o tratamento analítico, também serve à transferência. A respeito do encontro analista-analisando, ele diz (ibid.):

[...] esperamos que ele despeje um dilúvio de informações; mas, com frequência, a primeira coisa que acontece é ele nada ter a dizer. Fica silencioso e declara que nada lhe ocorre. Isso se evidencia como uma resistência ao recordar alguma coisa, a qual irá acompanhá-lo como compulsão à repetição no decorrer do tratamento analítico como forma de recordar (p. 166).

Mas o que de fato o paciente atuaria? De acordo com Freud (1914), ele atua suas inibições, suas atitudes inúteis, traços patológicos da personalidade e todos os seus sintomas. A análise é capaz de possibilitar ao sujeito uma superação das resistências e trazer à memória o material até então reprimido. Para superar essas memórias traumáticas relegadas ao esquecimento e à repetição inconsciente, o analista deve revelar a resistência até então desconhecida para o paciente de modo a se familiarizar com ela. Contudo, é preciso que se dê um tempo de elaboração ao paciente, para que, de fato, possa ultrapassá-la.

Outro aspecto visto na clínica freudiana estaria ligado ao manejo das transferências e ao uso delas como forma de resistência com o objetivo de dificultar o processo analítico. A transferência aparece na psicanálise como resistência porque as forças que estabeleceram o vínculo transferencial se erguerão a fim de conservar o novo estado das coisas (FREUD, 1912). Dessa maneira, os fragmentos da vida cotidiana do

\footnotetext{
74 No texto "A dinâmica da transferência" (1912), Freud fala que a transferência não é exclusiva da Psicanálise, mas sim à própria neurose. Nela o paciente “(...) está reexperimentando relações emocionais que tiveram sua origem em suas primeiras ligações de objeto" (Freud, 1925 [1924], p. 47).
} 


\section{RevistAleph}

paciente serão revividos na transferência, estando presentes também as resistências à mudança dos seus sintomas.

Uma intensificação de sua produção estaria presente no que Freud (1915) nomeou de agent provocauter (agente provocador), uma forma de transferência erótica ${ }^{75}$. Nela haveria um aumento do estado amoroso do paciente que consistiria em grande dificuldade para o analista. Sigmund afirma que seria possível que os sentimentos amorosos da paciente pudessem continuar sem que houvesse 0 complemento físico e, com isso, poderiam ser conduzidos a outras finalidades de tratamento da neurose, usando o amor transferencial como ferramenta de cura.

A resistência também pode ser decorrente da frustração. Na produção das neuroses a frustração opera quando há ausência do objeto real do mundo externo que atendia às exigências de amor do indivíduo sadio (FREUD, 1912). Ou seja, existia uma libido que se desenvolveu ao longo da vida do indivíduo por causas internas e externas. Em algum momento do desenvolvimento sexual, essa libido sofreu uma frustração quando esse objeto foi afastado sem que um substituto ocupasse seu lugar. Freud diz simplesmente: "A frustração tem efeito patogênico por represar a libido (...)" (ibid., p. 249). Sendo assim, a frustração por motivo de ausência do objeto faria a libido represada ir para o corpo, sob a forma de um sintoma. A resistência, nesse caso, compareceria como maneira de impedir a elaboração/superação da frustração que a ausência do objeto provocou, já que o sintoma "realiza", ainda que parcial e equivocadamente, a libido frustrada.

As críticas à psicanálise também foram vistas por Sigmund como formas de resistência. No texto Cinco Lições em Psicanálise (1910 [1909]), a terceira lição mostra as observações freudianas sobre as críticas tecidas à sua teoria, feitas por pessoas familiarizadas com o pensamento científico e que lhes exigem exatidão nos resultados. Mostra-se enfático no que diz respeito aos mecanismos de defesa erigidos por estas pessoas:

\footnotetext{
${ }^{75}$ A transferência erótica é representada pela atuação de um material reprimido que, não conseguindo emergir em forma de lembrança, recai sobre a figura do analista, pois a resistência impossibilitou a rememoração.
} 


\section{RevistAleph}

Quer a Psicanálise tornar conscientemente reconhecido aquilo que está reprimido na vida mental, e todo aquele que a julga é homem com as mesmas repressões, mantidas talvez à custa de penosos sacrifícios. Neles devem levantar-se, pois, as mesmas resistências, como nos doentes e estas se revestem facilmente das roupagens da impugnação intelectual [...] (p. 51).

Podemos pensar, sob esse prisma, que o entendimento freudiano sobre os críticos da Psicanálise, ainda reverbera nos tempos atuais. Apesar da "liberação sexual" atual e de todo o suposto avanço científico, a moral sexual ${ }^{76}$ predominante ainda impede inúmeras vezes que os estudos em torno da sexualidade sejam vistos de forma positiva. O fortalecimento do conservadorismo religioso atual é um sinal dessas resistências, cuja solução de compromisso (sintomática portanto) é a busca por uma figura de autoridade que lhes diga o que é certo ou errado nessa área tão opaca e enigmática...

Na segunda tópica, Freud (1926) define outros tipos de resistência: 1) as que provêm do eu [ego] (resistências do recalque, da transferência, como ganho secundário); 2) as que surgem do isso [id] (e necessitam de perlaboração ${ }^{77}$ ); e, 3) as resistências que advêm do supereu [superego]. Estas últimas estariam baseadas na necessidade de autopunição e consistiriam nas mais obscuras de todas elas.

Em seu trabalho A questão da análise leiga, Freud (1926) reflete sobre as impossibilidades de superação das resistências na análise, considerando que a marca do recalque nos neuróticos sempre incidirá na clínica na forma de dois desejos opostos: a cura e a não cura. Sobre isso, ele responde: "O paciente deseja ser curado - mas ele também deseja não ser. Seu ego perdeu a unidade, e por esse motivo sua vontade também não tem qualquer unidade. Se isto não fosse assim, ele não seria nenhum neurótico" (p. 218).

\footnotetext{
${ }^{76}$ Esse trecho faz alusão ao texto Moral Sexual Civilizada e Doença Moderna (FREUD, 1908), em que o autor discorre sobre pulsão sexual, moralidade e cultura.

77 Entende-se por perlaboração o “(...) trabalho de "incorporação" da superação da resistência e de assunção de uma nova conformação do ego" (OLIVEIRA, 2009, p. 122).
} 


\section{RevistAleph}

\section{Das resistências iniciais da pesquisadora e de alguns sujeitos encontrados nas escolas}

A primeira iniciativa da pesquisadora de entrar em uma escola recebeu resposta imediata de uma professora que compunha o quadro do colégio federal: "Você não vai conseguir entrar lá para falar de violência" (SIC). Ciente das dificuldades que talvez fossem particulares àquela docente com relação ao tema, foi realizado o primeiro contato com o colégio. As resistências, até então manifestas apenas na fala da docente, foram percebidas também pela pesquisadora, ao sentir dificuldades de entrar no colégio de aplicação. Aquela fala parecia uma espécie de "sentença" que causava certo temor em transpor os portões da escola, e ressoava como uma forma de desmotivação.

O portão trancado foi a primeira observação marcante. Por se tratar de um período atípico no calendário escolar, a dinâmica havia sido alterada. No entanto, naquele momento, o fato de a escola estar "trancada" produziu intensa ansiedade e medo de propor uma pesquisa, realçando nossas próprias resistências em "mexer" com esse tema supostamente reprimido.

Dessa forma, optamos por um período de "sensibilização do campo", onde se pudesse acompanhar a rotina da escola, a princípio sem abordar diretamente os professores. Foram realizadas visitas preliminares a uma escola Municipal e outra Federal, sendo possível aproximar-se do tema da violência na(s) escola(s) a partir das falas de pessoas da direção, da Orientadora Educacional, de alguns professores e alunos.

No colégio Federal, a entrada em campo se deu através da possibilidade de estagiar no setor de Orientação Educacional. O trâmite para a entrada foi bastante burocratizado, o que refletia certa resistência, para além do controle necessário, daqueles que faziam parte da instituição. O processo para o início do estágio durou uma semana, tendo em vista alguns aspectos: desencontros nos horários fornecidos para o recebimento dos documentos, adiamento do início do estágio por motivo de provas escolares e por outros alegados pela Orientadora Educacional.

Neste colégio, a experiência de estágio se deu por um dia, uma vez que houve diversas trocas de horário por parte da Orientadora Educacional, tanto por motivos pessoais quanto institucionais (reuniões, passeio escolar e provas dos alunos), que não coincidiam com o horário acordado e conflitavam com a disponibilidade da 


\section{RevistAleph}

pesquisadora. Nesse momento, indagamos: as constantes dificuldades apresentadas pela Instituição não seriam também capazes de provocar mais resistências à consecução da pesquisa?

Durante a sensibilização ${ }^{78}$ no colégio Estadual, foi possível perceber algumas questões referentes ao convívio entre alunos e entre alunos e professores. As tensões que marcam os encontros escolares nos fazem lembrar daquilo que Freud denominou como ambivalência, em que todas as relações transferenciais, ou seja, que comportam uma afetividade inconsciente, implicam em moções de amor e de ódio. A respeito da transferência, ele afirma “(...) a transferência é, ela própria, apenas um fragmento da repetição e que a repetição é uma transferência do passado esquecido" (FREUD, 1910, p. 197).

A transferência, surge também como resistência no setting analítico e pode ser entendida analogamente na relação professor-pesquisador como uma forma de relação transferencial marcada por identificação e agressividade, cujas resistências emanam tanto por parte do pesquisador quanto por parte do entrevistado.

Outra experiência de sensibilização aconteceu num colégio público pertencente à esfera municipal, em nível de estágio na sala dos professores e sala de aula. Ali, foi possível iniciar a construção de um processo de escuta das resistências para, em seguida, estabelecer questões para entrevistas semi-estruturadas. Nessa experiência também houve contato com o tema violência, trazido espontaneamente através dos próprios funcionários da escola. De pronto, houve a fala de um deles: "Chegou esse povo cheio de teoria", referindo-se à entrada de pesquisadores na Instituição. Na sala de aula, esta mesma professora responde ao seu aluno que a pesquisadora estava ali para "ver como vocês se comportam e observar" (SIC). Nesse sentido, foi possível observar o imaginário construído para aquela professora sobre o papel do pesquisador como aquele que vigia (e talvez pune) (FOUCAULT, 1975/2019) ${ }^{79}$.

\footnotetext{
78 Esse modo de fazer pesquisa é trazido por Ferreira e Moura (2005) e diz respeito ao estudo preliminar à coleta de dados, com intuito de aproximar-se do campo e levantar questões pertinentes ao tema.

${ }^{79} \mathrm{Não}$ analisamos aqui as resistências do ponto de vista foucaultiano, que estão ligadas à esfera micropolítica, cuja máxima seria: "Onde há resistência, há poder". Evocamos a genealogia foucaultiana naquilo que representa a punição e disciplina como dispositivos, por ventura, traumáticos e violentos, inscritos no insconsciente (social).
} 


\section{RevistAleph}

Essa fala parece representar a atuação de sentimentos hostis e resistências inconscientes em relação a um olhar externo à instituição.

Durante o período de sensibilização no colégio Municipal uma professora relatou ter sofrido violência na escola em que trabalhou, abordando a agressividade entre alunos e dos pais para com ela. Contou sobre a ausência de psicólogos na Instituição, assim como de pedagogos e funcionários no pátio, estes últimos, segundo ela, afastados por motivos de saúde. Após sofrer ameaça por parte da mãe de um aluno de quem havia chamado a atenção (SIC), relatou ter sofrido crises de pânico e precisado de remédios de "tarja preta". Entretanto, afirmou que não realizou acompanhamento psicoterápico.

A professora passou o seu contato para continuarmos a conversa, mas não esteve presente nos dias subsequentes e não respondeu ao nosso telefonema. Supomos que o contato com a pesquisadora gerou mal-estar nessa docente e que a rememoração do conteúdo traumático produziu resistências que impossibilitaram a consecução de sua escuta.

\section{Das resistências no campo e a escola "ocupada"}

Foi possível perceber que a entrada em uma escola, no enquadre de uma pesquisa, é bastante regulada, o que produz um efeito de "ricochete". A dificuldade de iniciar o trabalho em campo também foi percebida como ansiedade e medo de propor uma pesquisa no espaço escolar. Essas resistências foram vencidas a partir da insistência em "ocupar" esse espaço, ou seja, na repetição das tentativas de entrada, na permanência ali e na superação de mecanismos burocráticos que, supomos, representam igualmente a própria resistência institucional.

Durante o período da pesquisa, ocorreu uma experiência numa escola ocupada. Esta escola estava fazendo parte do movimento de secundaristas em luta, também conhecida como "Movimento Ocupa" ocorrido em 2016. Nele, os alunos da escola

\footnotetext{
${ }^{80} \mathrm{O}$ movimento Ocupa foi uma mobilização estudantil ocorrida em 2016 e que correspondeu a uma série de manifestações e ocupações de escolas e universidades brasileiras.
} 


\section{RevistAleph}

haviam tomado a frente da organização da escola, estando presentes todos os dias, integralmente, e reivindicando por melhorias na sua escola e na educação pública em geral. A escola foi constantemente visitada e "ocupada" por pesquisadores e estudantes de outras instituições e, ainda assim, houve mais uma vez dificuldades em adentrar a escola. Ao visitar pela primeira vez aquele espaço e encontrar o portão trancado, houve novamente receio em propor a pesquisa.

Nesta visita, uma professora-pesquisadora de uma escola Federal também tentava entrar na escola para visitação e pesquisa. Enfim, a entrada se deu a partir do nosso contato com um aluno ocupante, que solicitou a abertura do portão. Houve concordância em relação às dificuldades em adentrar numa escola por parte da pesquisadora, professora e do próprio aluno. A professora diz, a respeito das dificuldades em entrar na escola: "- Senti como se não fosse uma luta minha, e sim deles, dos alunos." Então, os sentimentos de inadequação e não pertencimento de cada qual àquele espaço foram debatidos entre os três.

O aluno da Ocupação apresentou a escola e falou sobre dados do movimento grevista. De acordo com ele, dos 15 professores em greve naquela escola, apenas um era contra. Ele comentou que tratava-se de uma professora religiosa e achava que não era fazendo greve que as coisas iriam se resolver (SIC). Outros assuntos conversados diziam respeito aos materiais sem uso, encontrados estocados, logo, desperdiçados, como livros e tablets. Relatou sobre a violência nas ruas sofrida pelos alunos negros, mesmo quando uniformizados.

O acolhimento do estudante foi fundamental para a superação das resistências iniciais, pois, como uma professora externa ao colégio afirmou: "A escola em funcionamento normal parece ter um olho, a gente não se sente à vontade" (SIC). Sendo assim, as resistências iniciais provocadas pelo mal-estar em ocupar o espaço diminuíram. A partir de então, a escola ocupada havia se tornado um lócus de pesquisa e encontros para debates e não provocava mais tanto medo naqueles que entravam no 


\section{RevistAleph}

espaço, mesmo sendo marcada por inúmeras ameaças violentas do movimento "Desocupa", ${ }^{81}$ do tráfico e da comunidade em geral.

\section{Dos caminhos da pesquisa}

A pesquisa se iniciou com o levantamento bibliográfico sobre o conceito de resistência em relação à temática que engloba psicanálise e educação. Diante da escassez de produções, o estudo dirigiu-se para o aprofundamento desse conceito nas Obras Psicológicas Completas de Sigmund Freud, concomitantemente à entrada da pesquisadora para sensibilização do campo.

Após o período de sensibilização, foi realizada uma revisão bibliográfica com o intuito de preparar o material de análise. Além do projeto para apresentação nas escolas (o que permitiu formalmente a entrada da pesquisadora), foi construído nesse período um roteiro de entrevista semiestruturada com perguntas sobre o modo como os professores compreendem a violência na escola, com um breve levantamento sociodemográfico, um "termo de consentimento livre e assistido" (declarando o anonimato da escola e do entrevistado e indagando se concordaria ou não com a gravação das entrevistas), de modo a confirmar o sigilo das informações pessoais. Após essa elaboração, voltamos de forma mais instrumentalizada para o campo, enfrentando novas tentativas de entrada em duas escolas: uma em nível Federal (já visitada anteriormente) e outra em nível Estadual ("ocupada").

$\mathrm{Na}$ escola federal o envio do projeto aconteceu no final do mês de abril e foi aprovado no prazo de um mês. Nesse tempo, passou pela avaliação do setor de estágios, da coordenação geral e da coordenação das séries. As respostas eram recebidas nas visitas que a pesquisadora realizava semanalmente com o objetivo de saber sobre a aprovação ou não do projeto.

A apresentação do projeto ocorreu durante a reunião de professores através da coordenadora geral, que recolheu os nomes dos professores interessados bem como

\footnotetext{
81 O Movimento "Desocupa" foi uma mobilização contrária ao movimento “Ocupa”, com objetivo de retomar as aulas, justificando que as ocupações não eram legítimas.
} 


\section{RevistAleph}

os respectivos horários colocados em disponibilidade para as entrevistas. Do grupo de trinta professores, conforme relatado pela coordenadora, quatro disponibilizaram-se a participar. Nas entrevistas realizadas, as perguntas giravam em torno do tema violência e da percepção do professor no que diz respeito à sua posição e àquilo que pensava ser a posição da escola em relação ao tema.

A pesquisa pautou-se num estudo qualitativo sobre os relatos dos professores e contou com a sua definição sobre violência escolar. Ao todo foram realizadas quatro entrevistas contendo em média uma hora de gravação cada uma. A transcrição foi feita ipsis litteris e alguns fragmentos do relato foram utilizados para análise das resistências presentes.

A quarta entrevista não pôde ser gravada integralmente por motivos de defeito no aparelho, que interrompeu a gravação da entrevista antes da conclusão. Na escola Estadual, a entrada para pesquisa se deu de forma diferenciada, pelo motivo da escola estar em momento de greve dos professores e ocupação dos alunos. Devido à ausência da direção na escola, não foi possível encaminhar o projeto, no entanto, a pesquisadora esteve ali presente durante dois meses, onde foi possível acompanhar uma reunião de professores do SEPE (Sindicato dos Profissionais de Educação do Rio de Janeiro) e realizar uma forma de escuta em grupo sobre as violências sofridas pelos alunos no decorrer do período de ocupação. A orientadora desta pesquisa participou conjuntamente de alguns encontros do grupo de estudantes que ocupavam a escola, pois havia um pedido explícito de que estavam "precisando de uma psicóloga". A partir desses encontros de conversação com o grupo de estudantes, visando um efeito terapêutico, também foi possível observar as resistências presentes no trabalho de pesquisa e nos sujeitos envolvidos nesta dinâmica.

\section{Análise dos dados e discussão teórica}

Os quatro professores que se disponibilizaram para participar das entrevistas demonstraram, cada um à sua maneira, resistências para tratar sobre o assunto. Os pontos salientados acima, conforme colocados por Freud a respeito do modo como as 


\section{RevistAleph}

resistências comparecem na análise, foram observados durante as entrevistas, sobretudo nos atrasos, nos esquecimentos, na retenção de informações importantes e na interrupção de ideias. O fenômeno que se destacou nos relatos dos professores foi a interrupção nas falas na forma de silêncio (apontados entre parênteses neste relatório) e que consideramos "(...) tão decisivos quanto os de uma palavra pronunciada" (NASIO, 2010).

Nasio (2010) ainda destaca o pensamento freudiano, que considera o silêncio ao tratar do recalque e, mais particularmente, da pulsão de morte. Além das associações em vista do desprazer psíquico, Freud (1912) também fala sobre o silêncio que comparece em função da transferência, pela ligação de ideias à figura do médico e que se transformam em recusa de falar.

Dessa forma, a escuta da pesquisadora-psicanalista não se voltou somente para as ideias trazidas pelos professores a respeito do tema violência, e sim, para os pontos em que eles silenciaram. O que não pode ser dito e se presentifica no silêncio do entrevistado para o pesquisador? O que é o silêncio no encontro entre pesquisadoranalisado? Seria uma revivescência de traços traumáticos atualizados na transferência, que ora se mostra de forma afetuosa, ora se mostra hostil (FREUD, 1912)? Essa ambivalência de sentimentos foi considerada pelas pesquisadoras como passível de ser elaborada a partir da palavra que ressignifica as experiências na escola.

Thomas (apud NASIO, 2010), revisita a história do esquecimento da palavra Signorelli por Freud, para afirmar que existiram três tipos de silêncios presentes no esquecimento do nome próprio deste artista. O primeiro seria da inibição, quando Freud silencia a associação de ideias por medo das rechaças de seu amigo; o segundo tempo, da incorporação da resistência e o terceiro, da repetição ligada à pulsão de morte. Pensamos, em primeiro lugar que, dada a brevidade dos encontros com os professores, a interrupção de ideias ocorreu por uma inibição frente à imagem da pesquisadora. Outro fator provável para analisar a recorrência do silêncio seria que, na repetição desse "ato vazio" do silêncio na fala sobre a violência, haveria um aspecto traumático, ou seja, típico da atuação silenciosa da pulsão de morte. A maior violência sofrida seria impronunciável e inaudível. 


\section{RevistAleph}

Como Thomas (ibid.) ainda afirma: "Se nosso trabalho de analista, às voltas com uma experiência que é a prática de um discurso, implica que nossa referência seja a palavra, então o silêncio é seu ponto de parada. Mais, o silêncio é o efeito de uma palavra em espera (p. 83)". Nesse sentido, o que a palavra em espera poderia representar para os professores? Uma vez que o pesquisador-psicanalista intervém no manejo com as resistências dos professores, seriam esses silêncios em parte substituídos por lembranças recalcadas e pela sua implicação diante das produções violentas que recaem sobre si e que se perpetuam no fazer pedagógico na escola? Ou as resistências expressas no silêncio seriam a expressão de um vazio impossível de se representar, típico da condição traumática da vivência cotidiana da violência nas escolas?

Outro mecanismo de defesa observado na fala dos professores foi a projeção. A pesquisa pôde considerar que os professores falam da violência que sofrem a partir das vivências de seus alunos. É importante considerar que a entrevistadora em nenhum momento localizou a violência nos alunos, no entanto, os professores tenderam a considerar que se tratava de uma pesquisa sobre violência entre alunos. Todos os professores destacaram as consequências negativas da violência "velada", "silenciosa" no contexto de seu trabalho, o que concluímos ser um fator que contribuiu para dificuldades na exposição do professor a respeito dos seus sentimentos.

Por tratar-se de uma escuta psicanaliticamente orientada, a "associação livre" de ideias e a "atenção flutuante" foram as técnicas básicas utilizadas. Os dados recolhidos foram transcritos de igual forma; sendo assim, algumas frases mostrar-se-ão incompletas devido à interrupção de ideias no próprio fluxo de pensamento do entrevistado, algo considerado como produção da resistência no encontro com a pesquisadora-psicanalista.

De outro lado, o trabalho de pesquisa na Ocupação (dos estudantes secundaristas) reafirmou mais uma vez o grave problema relatado em pesquisas anteriores (ARREGUY, 2014), sobre a ausência de psicólogos nas escolas públicas. O encontro com os alunos foi importante para a escuta das dificuldades encontradas por eles em relação à violência física e à violência simbólica (BOURDIEU, 2000). Pensamos 


\section{RevistAleph}

que a escuta das pesquisadoras-psicanalistas e as suas presenças físicas serviram sobretudo como uma forma de holding (WINNICOTT, 1987) em relação à intensidade do sofrimento apresentado pelos estudantes secundaristas no momento da ocupação.

Os jovens que habitavam o chão da escola não se posicionavam mais como objetos, mas como sujeitos implicados na transformação social. Essa nova consciência que portavam, embora libertadora, trazia-Ihes sofrimento pela responsabilidade que acarretava, e mais ainda, pelos conflitos que passavam a enfrentar diante de pais e professores, antes acostumados à sua docilidade infantil. O conflito de gerações apareceu de modo pungente nas falas (e no pranto) dos sujeitos que participaram do grupo "terapêutico" de conversação. Winnicott (1964) já falara a respeito da tenacidade juvenil e da inveja que os adultos sentem dos jovens, afirmando:

É dada publicidade a cada ato de baderna juvenil porque o público não quer realmente ouvir ou ler a respeito dessas façanhas adolescentes que estão isentas de qualquer desvio anti-social. Além disso, quando acontece um milagre, como os Beatles, existem aqueles adultos que franzem o cenho, quando podiam soltar um suspiro de alívio - quer dizer, se estivessem livres da inveja que sentem do adolescente nesta fase (p. 178).

Embora consideremos que a Ocupação representaria o retorno do que foi recalcado na escola, e por esse motivo, fonte de resistências e repressão, acreditamos que a ferramenta da escuta, tal qual na entrevista dos professores, seja importante no enfrentamento das violências vividas e relatadas pelos estudantes. Por outro lado, as pesquisadoras vivenciaram as conversações de uma posição duplamente engendrada, intermediária entre o adulto "opressor" e os jovens "inexperientes". As pesquisadoras eram adultas, diferentes, porém, confidentes dos estudantes, buscando valorizar suas falas e acolher a dor que relatavam, sobretudo em relação às suas frustrações durante a desocupação da escola e a necessidade de se reorganizarem internamente como jovens, capazes de responsabilidades, que teriam que sustentar dali em diante. 


\section{RevistAleph}

\section{Elementos das entrevistas e considerações finais}

A escuta sobre as resistências através do método da associação livre foi a técnica empregada por Freud (1910) a partir de sua clínica:

Mandamos o doente dizer o que quiser, cônscios de que nada the ocorrerá à mente senão aquilo que indiretamente dependa do complexo procurado. Talvez lhes pareça muito fastidioso este processo de descobrir os elementos reprimidos, mas asseguro-lhes, é o único praticável (p. 45).

Nesta pesquisa, tomamos paralelamente o universo escolar em relação às técnicas clínicas, dada a pertinência e pregnância de aspectos transferenciais no contexto educacional. A análise das resistências, e da transferência como uma forma de resistência, privilegiou a ação dos professores, mas esteve também interessada nas defesas erigidas pela pesquisadora no decorrer do processo, sendo possível concluir que a entrada no campo de pesquisa, pode provocar resistências de ambos os lados - dos docentes e da própria pesquisadora. Alguns motivos foram fonte de ansiedade: a excessiva burocratização na entrada em campo, o portão trancado das escolas, a ausência de retorno prometido em relação à aprovação da pesquisa e os atrasos dos docentes.

Em relação aos professores, todos que se dispuseram a participar da pesquisa se mostraram solícitos a fornecer material para análise. O significante "violência" utilizado como mote deu margem a associações diversas, no entanto, foi corriqueira a atribuição do fenômeno à "violência entre alunos". Pouco se falou a respeito da violência que o professor sofre pela sua "hierarquia" superior, ou em relação às próprias dificuldades enfrentadas pela categoria (baixos salários, falta de reconhecimento), tampouco das condições precárias (infraestrutura, salário, contingente e qualidade da formação dos profissionais, etc.) que se encontram nas instituições. Houve, no entanto, falas sobre o adoecimento dos professores e a fuga de situações de violência. A forma como falavam sobre a violência que os acometia era um pouco escamoteada. Dois professores entrevistados mostraram que percebiam que a violência dos alunos para com eles não deveria ser tomada pessoalmente, demonstrando um conhecimento 


\section{RevistAleph}

intrínseco (na prática e não teórico) sobre o conceito de transferência. A "violência dos professores contra os alunos" pouco foi mencionada, mas apareceu na alusão às categorias de "indiferença", "não reconhecimento", "punição".

O estudo das resistências apontou uma nova demanda: o entendimento sobre o silêncio presente nesses discursos do ponto de vista psicológico, que aponta para uma inibição do conteúdo recalcado, se considerada a primeira tópica freudiana, ou de uma impossibilidade de representação, efeito do traumático expresso pela pulsão de morte. Indo por outro prisma, social, pensamos que talvez esse silêncio também signifique a própria impossibilidade do professor de falar sobre o mal-estar de que padece, devido à violência sofrida em sua profissão; não se tratando, portanto, somente das agressões vivenciadas pelos seus alunos.

Não intencionamos resolver a intensidade desse fenômeno da violência, mas lançar luz sobre outras problemáticas que subjazem ao "ser professor" atualmente. Ademais, houve muitas falas dos professores que trouxeram um caráter de "resistência", na medida em que pausavam a enunciação, mudavam o rumo da questão quando apresentavam contradições e ambivalências no que diziam, e, ainda, quando tentavam se adequar, sobretudo perguntando para a pesquisadora se estavam falando a coisa que deveria ser dita.

Por outro lado, houve um caráter de "perlaboração" na fala sobre as violências nas escolas. Na medida em que iam falando, puderam fazer uma espécie de construção subjetiva de suas concepções de violência, muitas vezes acompanhada de uma retrospectiva a aspectos traumáticos de suas carreiras. Nesse sentido, as entrevistas com os professores promoveram um espaço, ainda que pontual, para a escuta e elaboração de seus sofrimentos.

Žižek ${ }^{82}$, em entrevista dada à TV Cultura propõe uma "desfetichização" do conceito de violência. De acordo com ele, há uma cultura da tolerância liberal que prega uma sociedade sem violência. Contudo, há que se pensar a violência como uma forma de transformação social, ou seja, como uma expressão subjetiva que sempre traz em

\footnotetext{
${ }^{82}$ Disponível em https://tvcultura.com.br/videos/13430 slavoj-zizek-08-07-2013.html . Acesso em 19 de setembro de 2019.
} 


\section{RevistAleph}

seu bojo uma série de significações a serem compreendidas, em vez de simplesmente julgadas e punidas.

Pensamos que essa violência - praticada em ato por alunos e professores - é remediável à medida que for compreendida como uma tentativa de transformação nos modos de ser dentro da Instituição, ou seja, uma tentativa de elaboração a partir da "catástrofe" que produz vida (FERENCZI, 1924/2011). A palavra transformadora, nesse sentido, vai além do manejo com as resistências (inconscientes), situando-se no campo das relações de poder (FOUCAULT, 1979/2002) que fazem parte da escola.

Por seu caráter social, o silêncio já esteve na citação do ativista político Martin Luther King Jr: "O que me preocupa não é nem o grito dos corruptos, dos violentos, dos desonestos, dos sem caráter, dos sem ética... O que me preocupa é o silêncio dos bons". Dessa forma, pudemos situar nossa pesquisa nesse mesmo pensamento, sem considerar somente as produções violentas, mas de que forma o silêncio se mostrou presente como fator de resistência à mudança. 


\section{RevistAleph}

\section{Referências}

ABRAMOVAY, Miriam. (Coord.) Cotidiano das escolas: entre violências. Brasília: UNESCO, Observatório da Violência, Ministério da Educação, 2005.

ARREGUY, M. E.. Violência e ausência de psicólogos nas escolas. Physis, Rio de Janeiro , v. 24, n. 1, p. 229-252, Mar. $2014 \quad$ Available from<http://www.scielo.br/scielo.php?script=sci_arttext\&pid=S0103-

73312014000100229\&lng=en\&nrm=iso> access on 02 Feb. 2016. http://dx.doi.org/10.1590/\$0103-73312014000100013

ARREGUY, M; COUTINHO, L.G.. Considerações sobre afetos e violências no espaço escolar: conversações com professores. Educação em Revista. Belo Horizonte, v.31, n.03, p. 279-298, Julho-Setembro, 2015.

BOURDIEU, P. Sobre el poder simbolico. In: Intelectuales, política y poder. Buenos Aires: Eudeba, 1990. p. 65-73.

COSTA, J F. (2003). Violência e Psicanálise. Rio de Janeiro: Graal.

FERENCZI, S. (1924). Thalassa, ensaio sobre a teoria da genitalidade. In Obras Completas Psicanálise III. São Paulo, SP: Martins Fontes, 2011.

FERENCZI, S.(1934). Reflexões sobre o trauma in Obras Completas - Psicanálise IV. São Paulo: Martins Fontes, 2011.

FOUCAULT, M.(1975). Vigiar e punir: nascimento da prisão. Tradução de Lígia M. Pondé Vassalo. Petrópolis, RJ: Vozes, 2019.

FOUCAULT, M.(1979). Microfísica do poder. Rio de Janeiro: Graal, 2002.

FREIRE, P.. Pedagogia da Autonomia - Saberes necessários à prática educativa. São Paulo: Brasil: Paz e Terra, 1996.

FREUD, S.. Casos clínicos [1893-1895]. In: Estudos sobre a histeria Edição Standard Brasileira das Obras Psicológicas Completas de Sigmund Freud. Rio de Janeiro: Imago, 1996. v. II.

Projeto para uma psicologia científica (1950 [1895]) In: Publicações prépsicanalíticas e esboços inéditos. Edição Standard Brasileira das Obras Psicológicas Completas de Sigmund Freud. Rio de Janeiro: Imago, 1996. v. I.

Observações adicionais sobre as neuropsicoses de defesa (1896) In: Primeiras publicações psicanalíticas. Edição Standard Brasileira das Obras Psicológicas Completas de Sigmund Freud. Rio de Janeiro. Rio de Janeiro: Imago, 1996. v. III.

O mecanismo psíquico do esquecimento (1898) In: Primeiras publicações psicanalíticas. Edição Standard Brasileira das Obras Psicológicas Completas de Sigmund Freud. Rio de Janeiro . Rio de Janeiro: Imago, 1996. v. III.

Lembranças encobridoras (1899) In: Primeiras publicações psicanalíticas. Edição Standard Brasileira das Obras Psicológicas Completas de Sigmund Freud. Rio de Janeiro . Rio de Janeiro: Imago, 1996.v. III.

. O trabalho do sonho. (1900) In: A interpretação dos sonhos. In: Edição Standard Brasileira das Obras Psicológicas Completas de Sigmund Freud. Rio de Janeiro: Imago, 1996. v. IV. 


\section{RevistAleph}

Moral sexual "civilizada" e doença nervosa moderna (1908). In: "Gradiva" de Jensen e outros trabalhos. Edição Standard Brasileira das Obras Psicológicas Completas de Sigmund Freud. Rio de Janeiro . Rio de Janeiro: Imago, 1996. v. IX.

As perspectivas futuras da terapêutica psicanalítica (1910). In: Cinco Lições de Psicanálise, Leonardo da Vinci e outros trabalhos. Edição Standard Brasileira das Obras Psicológicas Completas de Sigmund Freud. Rio de Janeiro. Rio de Janeiro: Imago, 1996. v. XI.

A dinâmica da transferência (1912). In: 0 caso Schreber, artigo sobre técnica e outros trabalhos. Edição Standard Brasileira das Obras Psicológicas Completas de Sigmund Freud. Rio de Janeiro. Rio de Janeiro: Imago, 1996. v. XII.

Recordar, repetir e elaborar (1914). In: O caso Schreber, artigos sobre técnica e outros trabalhos. Edição Standard Brasileira das Obras Psicológicas Completas de Sigmund Freud. Rio de Janeiro: Imago, 1996. v. XII.

A história do Movimento Psicanalítico, artigos sobre metapsicologia e outros trabalhos (1914-1916). Edição Standard Brasileira das Obras Psicológicas Completas de Sigmund Freud. Rio de Janeiro: Imago, 1996. v. XIV.

Além do princípio do prazer (1920). In: Um estudo autobiográfico, inibições, sintomas e ansiedade, análise leiga e outros trabalhos. Edição Standard Brasileira das Obras Psicológicas Completas de Sigmund Freud. Rio de Janeiro: Imago, 1996. v. XX.

A questão da análise leiga (1926) In: O futuro de uma ilusão, o mal-estar na civilização e outros trabalhos. Edição Standard Brasileira das Obras Psicológicas Completas de Sigmund Freud. Rio de Janeiro: Imago, 1996. v. XXI.

Inibições, sintomas e ansiedade (1926 [1925]). In: O futuro de uma ilusão, o malestar na civilização e outros trabalhos. Edição Standard Brasileira das Obras Psicológicas Completas de Sigmund Freud. Rio de Janeiro: Imago, 1996. v. XXI.

. O Mal-Estar na Civilização (1930 [1929]). In: O futuro de uma ilusão, o mal-estar na civilização e outros trabalhos. Edição Standard Brasileira das Obras Psicológicas Completas de Sigmund Freud. Rio de Janeiro: Imago, 1996. v. XXI.

Análise terminável e interminável (1937a). In: Moisés e o Monoteísmo, Esboço de Psicanálise e outros trabalhos. Edição Standard Brasileira das Obras Psicológicas Completas de Sigmund Freud. Rio de Janeiro: Imago, 1996. v. XXIII.

Construções em análise (1937b). In: Moisés e o Monoteísmo, Esboço de Psicanálise e outros trabalhos. Edição Standard Brasileira das Obras Psicológicas Completas de Sigmund Freud. Rio de Janeiro: Imago, 1996. v. XXIII.

GONDAR, J.. Ferenczi e o sonho. Cadernos de Psicanálise - Círculo Psicanalítico do Rio de Janeiro. Rio de Janeiro, v. 35, n. 29, p. 27-39, jul./dez. 2013.

LABAKI, M. E. P.. Hipocrisia e trauma: elaborações para uma metapsicologia da técnica em Ferenczi. J. psicanal., São Paulo, v. 47, n. 87, p. 179-194, dez. 2014. Disponível em $<$ http://pepsic.bvsalud.org/scielo.php?script=sci_arttext\&pid=S0103-

58352014000200011\&lng=pt\&nrm=iso> acesso em 14 fev. 2016.

LAPLANCHE, J. \& PONTALIS, J. B.. Vocabulário da Psicanálise. São Paulo: Martins Fontes, 1996.

KING, M. L.. As palavras de Martin Luther King. Seleção e introdução: Coretta Scott King. Rio de Janeiro: Editora Zahar, 2009. 


\section{RevistAleph}

NASIO; J. D. O silêncio em Psicanálise. Rio de Janeiro: Editora Jorge Zahar, 2010.

NOGUEIRA, M. A. \& NOGUEIRA, C. M.. Bourdieu \& e a educação. Belo Horizonte: Autêntica, 2004.

NOGUEIRA, C. M. M. \& NOGUEIRA, M. A. A sociologia da educação de Pierre Bourdieu: limites e contribuições. Educ. Soc., Campinas , v. 23, n. 78, p. 15-35, Apr. 2002 . Available from<http://www.scielo.br/scielo.php?script=sci_arttext\&pid=S0101-

$73302002000200003 \&$ Ing=en\&nrm=iso >.access on 02 Aug. 2016.

OLIVEIRA, D. C.. Silêncios: resistência e perlaboração, regressão e repouso. Cadernos de Psicanálise. Círculo Psicanalítico do Rio de Janeiro, 2009. Disponível em: http://cpri.com.br/imagenscadernos/10.Silencios resistencia e perlaboracao regressao e re pouso.pdf. Acesso em: 10 nov 2019

SANTOS, B. de S.. Um discurso sobre as ciências. Porto: Afrontamento, 1987 (6a edição)

TORRES, R. M.. Melhorar a qualidade da educação básica? As estratégias do Banco Mundial. In: HADDAD, S; WARDE, M.J; TOMMASI, L. de. O Banco Mundial e as Políticas Educacionais. São Paulo: Cortez Editora, 1996.

WINNICOTT, D. (1987). Privação e delinquência. Trad. de Álvaro Cabral. São Paulo: Martins Fontes, 1984.

ŽIŽEK, S. Violence. New York: Picador, 2008.

Data do envio: $30 / 09 / 2019$

Data do aceite:13/12/2019. 